7-19-2021

\title{
COVID-19 Deliveries: Maternal Features and Neonatal Outcomes
}

\author{
Viviana Zlochiver \\ Blair Tilkens \\ Ana Cristina Perez Moreno \\ Fatima Aziz \\ M. Fuad Jan
}

Follow this and additional works at: https://aah.org/jpcrr

Part of the Circulatory and Respiratory Physiology Commons, Family Medicine Commons, Female Urogenital Diseases and Pregnancy Complications Commons, Maternal and Child Health Commons, Obstetrics and Gynecology Commons, and the Virus Diseases Commons

\section{Recommended Citation}

Zlochiver V, Tilkens B, Perez Moreno AC, Aziz F, Jan MF. COVID-19 deliveries: maternal features and neonatal outcomes. J Patient Cent Res Rev. 2021;8:286-9. doi: 10.17294/2330-0698.1848

Published quarterly by Midwest-based health system Advocate Aurora Health and indexed in PubMed Central, the Journal of Patient-Centered Research and Reviews (JPCRR) is an open access, peer-reviewed medical journal focused on disseminating scholarly works devoted to improving patient-centered care practices, health outcomes, and the patient experience. 


\title{
COVID-19 Deliveries: Maternal Features and Neonatal Outcomes
}

\author{
Viviana Zlochiver, PhD, ${ }^{1}$ Blair Tilkens, DO,${ }^{2}$ Ana Cristina Perez Moreno, MD, PhD, ${ }^{1}$ Fatima Aziz, MD, ${ }^{3}$ \\ M. Fuad Jan, MBBS (Hons), MD ${ }^{4}$ \\ ${ }^{1}$ Advocate Aurora Research Institute, Advocate Aurora Health, Milwaukee, WI; ${ }^{2}$ Department of Internal Medicine, \\ Aurora St. Luke's Medical Center, Advocate Aurora Health, Milwaukee, Wl; ${ }^{3}$ Maternal Fetal Medicine Division, \\ Department of Obstetrics and Gynecology, Aurora Medical Center Grafton, Grafton, Wl; ${ }^{4}$ Aurora Cardiovascular and \\ Thoracic Services, Aurora Sinai/Aurora St. Luke's Medical Centers, Milwaukee, WI; University of Wisconsin School of \\ Medicine and Public Health, Madison, WI
}

\begin{abstract}
Integrated, data-driven criteria are necessary to evaluate delivery outcomes in pregnancies affected by severe acute respiratory syndrome coronavirus 2 (SARS-CoV-2) during the ongoing COVID-19 pandemic. This study analyzed maternal demographics, clinical characteristics, treatments, and delivery outcomes of 85 ethnically diverse, adult pregnant women who tested positive for SARS-CoV-2 at the time of delivery. Median maternal and gestational ages were 27 years (interquartile range [IQR]: 23-31) and 39 weeks (IQR: 37.3-40.0), respectively. Of the 85 SARS-CoV-2-positive participants, 67 (79\%) had no COVID-19 symptoms at the time of routine COVID-19 admission testing, 14 (16\%) reported mild COVID-19 symptoms, and 4 (5\%) presented severe COVID-19 symptoms that required hospitalization. Patients in the severe COVID-19 group had significantly longer hospitalizations than those with nonsevere COVID-19 (7 [IQR: 4.5-9.5] vs 2 [IQR: 2-3] days; P<0.01). Neonatal outcomes included $100 \%$ live births with a median 1-minute Apgar score of 8 and $15 \%$ preterm births. No neonatal deaths or vertical transmissions were reported, and all neonatal intensive care unit admissions were related to prematurity. Overall, maternal symptom prevalence and peripartum complication rates were low, suggesting a generally good prognosis for pregnant women with SARS-CoV-2 infections at the time of delivery. (J Patient Cent Res Rev. 2021;8:286-289.)
\end{abstract}

Keywords COVID-19 symptoms; pregnancy; maternal health; neonatal outcomes; SARS-CoV-2

$\mathrm{T}$ The potential risks of becoming pregnant during the ongoing COVID-19 pandemic are concerning, as pregnancy confers increased susceptibility to respiratory infectious diseases ${ }^{1-9}$ and pregnant research subjects were not included in COVID-19 vaccine trials. ${ }^{10,11}$ Although most human coronavirus infections are mild, the severe acute respiratory syndrome (SARS) and Middle East respiratory syndrome (MERS) viral epidemics of the past two decades have been especially grave, with high maternal mortality rates. ${ }^{1,12}$ In a recent morbidity and mortality report by the Centers for Disease Control and Prevention on 326,335 women of reproductive age (15-44 years) with COVID-19, pregnant women reported similar or milder symptoms than nonpregnant counterparts. Nonetheless, pregnant

Corresponding author: M. Fuad Jan, MBBS (Hons), MD, Aurora St. Luke's Medical Center, 2801 W. Kinnickinnic River Pkwy., \#880, Milwaukee, WI 53215 (wi.publishing18@aah.org) women were found to be more likely to be hospitalized and at increased risk for intensive care unit admission and receipt of mechanical ventilation (1.5\%) than nonpregnant ones $(0.9 \%)$, with similar risk of mortality. ${ }^{12,13}$

The timing of infection is a key factor to consider in the clinical management of pregnancies affected by severe acute respiratory syndrome coronavirus 2 (SARS-CoV-2), the viral strain responsible for COVID-19. Given the low occurrence of vertical transmission reported in the literature,,$^{1,3,14-20}$ it becomes important to understand the characteristics and outcomes of maternal COVID-19 in terms of pregnancies at the time of delivery. These unique challenges call for integrated, data-driven criteria to understand susceptibility to severe illness and minimize potential complications in the peripartum period.

This study sought to investigate maternal clinical characteristics and pregnancy outcomes in pregnant women infected with SARS-CoV-2 at the time of delivery to help inform patient management challenges in real inpatient settings. 


\section{METHODS}

All consecutive deliveries from adult pregnant women with a positive reverse transcriptase-polymerase chain reaction nasopharyngeal swab test result for SARS-CoV-2 admitted to any of 14 Advocate Aurora Health medical centers in Wisconsin and Illinois up to October 3, 2020, were included in this study. The first study participant to meet inclusion criteria was admitted on March 23, 2020.

The Advocate Aurora institutional review board approved the abstraction of data generated for routine clinical practice and waived the requirement for informed patient consent. A comprehensive retrospective review of maternal demographics, clinical characteristics, treatments, and delivery outcomes was performed, and participants were divided according to COVID-19 severity into 3 groups: asymptomatic (no COVID-19 symptoms reported), mild COVID-19 (symptoms not requiring hospitalization), and severe COVID-19 (symptoms requiring hospitalization).

Descriptive statistics were calculated and presented as median and interquartile range (IQR) for continuous variables and as percentage for categorical variables.

\section{RESULTS}

A total of 85 deliveries from adult, ethnically diverse, pregnant women who tested positive for SARS-CoV-2 at hospital admission were investigated. Median maternal and gestational ages were 27 years (IQR: 23-31) and 39 weeks (IQR: 37.3-40.0], respectively. Participant characteristics are summarized in Table 1.

Overall, symptom prevalence was low, with fever being the most common COVID-19 symptom reported (8\%), followed by dyspnea, cough, and loss of taste or smell (6\% each). Maternal SARS-CoV-2-positive status was an incidental finding of routine COVID-19 admission testing in $79 \%$ of patients (asymptomatic group, $n=67$ ), mild COVID-19 symptoms were present in $16 \%$ of patients (mild COVID-19 group, $\mathrm{n}=14$ ), and maternal COVID-19 symptoms were the primary reason for hospitalization in $5 \%$ of cases (severe COVID-19 group, $n=4$ ). Figure 1 illustrates symptom prevalence and distribution by group.

Maternal comorbidity rates also were low, with few complications during hospitalization. Of 36 participants with baseline creatinine laboratory tests at admission, 4 asymptomatic patients and 2 patients with severe COVID-19 developed a creatinine increase of $\geq 25 \%$ during the course of the hospitalization, and 1 severe COVID-19 patient went on to develop acute respiratory distress syndrome necessitating mechanical ventilation. Overall median length of stay was 2 days [IQR: 2-3]. When compared using Wilcoxon rank-sum test, patients in the severe COVID-19 group were found to have had significantly longer hospitalizations than those with nonsevere COVID-19 (7 [IQR: 4.5-9.5] vs 2 [IQR: 2-3] days; $\mathrm{P}<0.01$ ).

Table 1. Characteristics of Hospitalized SARSCoV-2-Positive Pregnant Women $(\mathrm{N}=85)$ at Delivery

\begin{tabular}{|c|c|}
\hline Characteristic & $\begin{array}{c}\mathbf{n}(\%) \text { or } \\
\text { median [IQR] }\end{array}$ \\
\hline Maternal age & 27 [23-31] years \\
\hline Gestational age & 39 [37.3-40.0] weeks \\
\hline \multicolumn{2}{|l|}{ Ethnicity } \\
\hline Hispanic & $33(39 \%)$ \\
\hline Caucasian & $28(33 \%)$ \\
\hline Black & $17(20 \%)$ \\
\hline Other & $7(8 \%)$ \\
\hline \multicolumn{2}{|l|}{ Signs and symptoms } \\
\hline Fever & $7(8 \%)$ \\
\hline Dyspnea & $5(6 \%)$ \\
\hline Cough & $5(6 \%)$ \\
\hline Loss of sense of taste or smell & $5(6 \%)$ \\
\hline Headache & $4(5 \%)$ \\
\hline Congestion and rhinorrhea & $3(4 \%)$ \\
\hline Fatigue & $2(2 \%)$ \\
\hline Sore throat & $2(2 \%)$ \\
\hline Sputum production & $1(1 \%)$ \\
\hline Nausea/vomiting & $1(1 \%)$ \\
\hline Diarrhea & $1(1 \%)$ \\
\hline Muscle aches & $0(0 \%)$ \\
\hline \multicolumn{2}{|l|}{ Comorbidities } \\
\hline Asthma & $9(11 \%)$ \\
\hline Hypertension & $6(7 \%)$ \\
\hline Dyslipidemia & $2(2 \%)$ \\
\hline Diabetes & $2(2 \%)$ \\
\hline Coronary artery disease & $1(1 \%)$ \\
\hline \multicolumn{2}{|l|}{ Management } \\
\hline Oxygen required & $6(7 \%)$ \\
\hline Ventilator use & $3(4 \%)$ \\
\hline Acute respiratory distress syndrome & $1(1 \%)$ \\
\hline \multicolumn{2}{|l|}{ Outcomes } \\
\hline Hospital stay & 2 [2-3] days \\
\hline Live births & $\mathrm{n}=92^{*}$ \\
\hline Preterm births & $13(15 \%)^{*}$ \\
\hline 1-minute Apgar score & 8 [8-9] \\
\hline $\begin{array}{l}\text { Neonatal SARS-CoV-2 detected } \\
\text { at } 24 \text { hours }\end{array}$ & $0(0 \%)$ \\
\hline Neonatal death & $0(0 \%)$ \\
\hline
\end{tabular}

*7 sets of twins were delivered, resulting in 92 live births; preterm birth percentage was calculated from total of 85 . $I Q R$, interquartile range; SARS-CoV-2, severe acute respiratory syndrome coronavirus 2. 

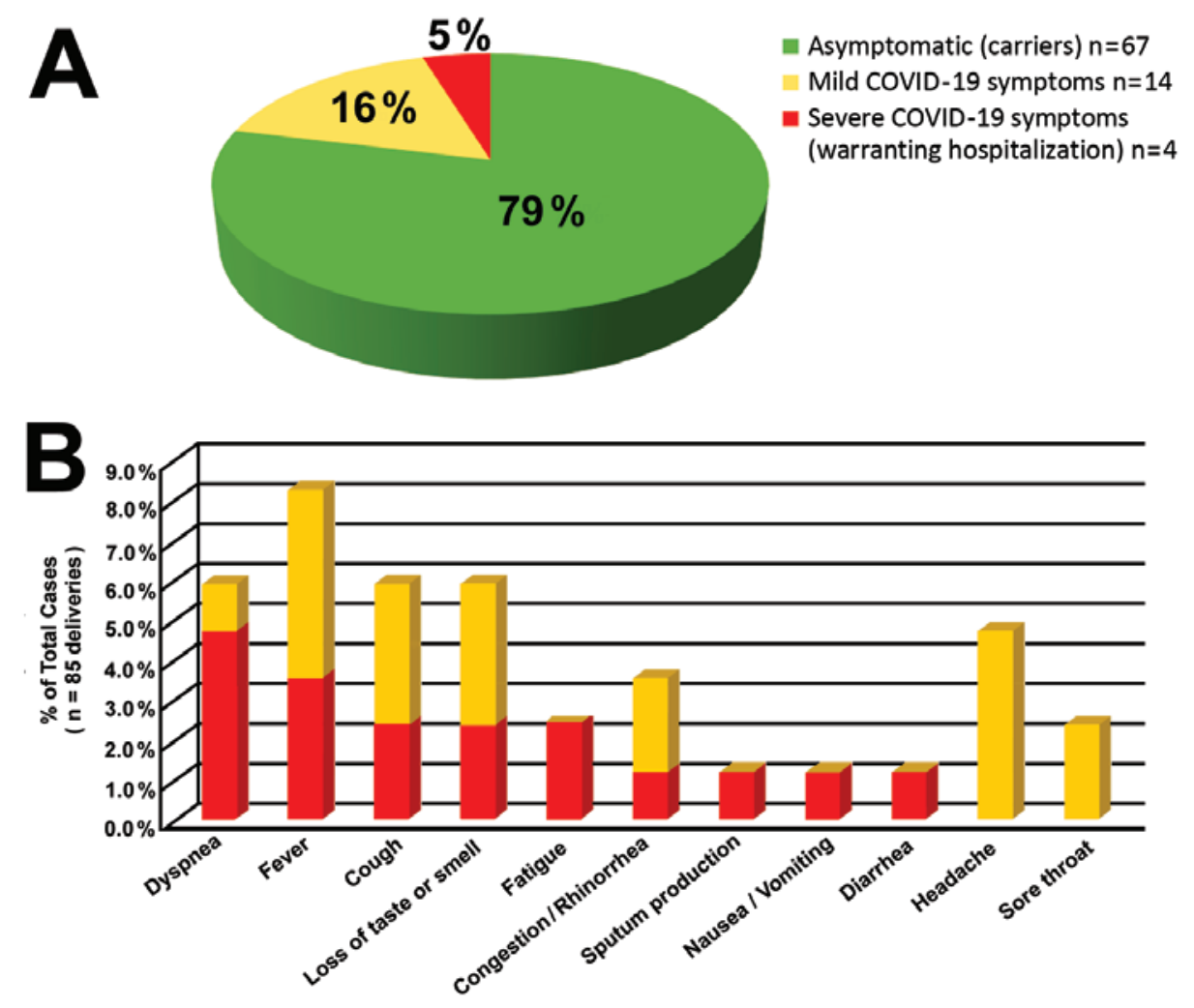

Figure 1. Maternal symptoms in severe acute respiratory syndrome coronavirus 2 (SARSCoV-2)-positive pregnancies at delivery. A: Patient distribution according to COVID-19 symptom severity. B: COVID-19 symptom prevalence in mildly and severely symptomatic patients.

Neonatal outcomes included $100 \%$ live births with a median 1-minute Apgar score of 8 and 15\% preterm births (ie, 13 of 85 total deliveries). Two deliveries (2.3\% of the overall cohort of 85 and $50 \%$ of the severe COVID-19 group of 4) were induced in the $33 \mathrm{rd}$ week of pregnancy: one due to preeclampsia in a twin pregnancy and the other due to worsening of COVID-19 symptoms in a pregnancy complicated by asthma. Prematurity was the only indication for neonatal intensive care unit admission. All neonates tested negative for SARS-CoV-2 infection 24 hours after birth.

\section{DISCUSSION}

The vast health system interrogated for this study is uniquely positioned to report on large sample populations of COVID-19-positive pregnancies. National COVID-19 surveillance registries lack hospitalization data to distinguish admissions for COVID-19-related circumstances (eg, worsening respiratory status) from hospital admission for pregnancy-related treatment or procedures (eg, delivery). This limitation makes it very difficult to assess whether the outcomes reported are attributable to the pregnancy, the COVID-19 infection, both, or neither.

As clinical and epidemiological data become available, risk and management of COVID-19 pregnancies become increasingly well-informed. ${ }^{1,17,18,21-23}$ Since submission of our manuscript, several other descriptive reports on maternal SARS-CoV-2 and deliveries affected by COVID-19 in single U.S. health systems have been published. ${ }^{24-26}$ Consistent with our findings, these studies report largely asymptomatic COVID-19 presentation in this patient population and no increased feto-maternal risks compared to SARS-CoV-2-negative cohorts.

Our study timeframe captured the initial experience of COVID-19 in the midwestern United States. During the months of April and early May 2020, COVID-19 hospitalizations saw a positive trend that decreased and plateaued in July until the end of our study in October 2020. Given that all pregnant women were screened for SARS-CoV-2 at admission during this timeframe, we were able to determine that the vast majority $(79 \%)$ of SARS-CoV-2 maternal infections at the time of delivery are asymptomatic and largely uncomplicated. Neonatal outcomes in our study were excellent; however, 2 of the 4 deliveries in pregnant women hospitalized for severe COVID-19 symptoms had to be induced prematurely.

Results from this retrospective study suggest overall good feto-maternal prognosis for pregnant women with SARS-CoV-2 infections at the time of delivery. Knowing that COVID-19 is unlikely to complicate deliveries endows physicians with data-driven criteria to prioritize minimizing the risk of contagion during lactation and neonatal care. 


\section{Patient-Friendly Recap}

- To better inform care for women with peripartum COVID-19 and their newborns, the authors analyzed delivery outcomes for 85 adult women who tested positive for SARS-CoV-2 shortly prior to giving birth at a multihospital health system in the U.S. Midwest.

- Most of the pregnant women testing positive for SARS-CoV-2 were asymptomatic, and none transmitted the virus to their babies.

-While there were few maternal or neonatal complications overall, 2 of the 4 women with severe COVID-19 symptoms requiring hospitalization had to be induced prematurely.

\section{Acknowledgments}

The authors thank Jennifer Pfaff for editorial preparation of this brief report and Brian Schurrer for assistance with the figure.

\section{Author Contributions}

Study design: Zlochiver, Aziz, Jan. Data acquisition or analysis: all authors. Manuscript drafting: Zlochiver, Jan. Critical revision: Zlochiver, Aziz, Perez Moreno, Jan.

\section{Conflicts of Interest}

None.

\section{References}

1. Di Mascio D, Khalil A, Saccone G, et al. Outcome of coronavirus spectrum infections (SARS, MERS, COVID-19) during pregnancy: a systematic review and meta-analysis. $\mathrm{Am}$ J Obstet Gynecol MFM. 2020;2(2):100107. CrossRef

2. Narang K, Enninga EAL, Gunaratne MD, et al. SARS-CoV-2 infection and COVID-19 during pregnancy: a multidisciplinary review. Mayo Clin Proc. 2020;95:1750-65. CrossRef

3. Elshafeey F, Magdi R, Hindi N, et al. A systematic scoping review of COVID-19 during pregnancy and childbirth. Int $J$ Gynaecol Obstet. 2020;150:47-52. CrossRef

4. Andrikopoulou M, Madden N, Wen T, et al. Symptoms and critical illness among obstetric patients with coronavirus disease 2019 (COVID-19) infection. Obstet Gynecol. 2020;136:291-9. CrossRef

5. Breslin N, Baptiste C, Gyamfi-Bannerman C, et al. Coronavirus disease 2019 infection among asymptomatic and symptomatic pregnant women: two weeks of confirmed presentations to an affiliated pair of New York City hospitals. Am J Obstet Gynecol MFM. 2020;2(2):100118. CrossRef

6. Castro P, Matos AP, Werner H, Lopes FP, Tonni G, Araujo Júnior E. Covid-19 and pregnancy: an overview. Rev Bras Ginecol Obstet. 2020;42:420-6. CrossRef

7. Mertz D, Lo CK, Lytvyn L, Ortiz JR, Loeb M; FluriskInvestigators. Pregnancy as a risk factor for severe influenza infection: an individual participant data meta-analysis. $B M C$ Infect Dis. 2019;19:683. CrossRef

8. Panahi L, Amiri M, Pouy S. Risks of novel coronavirus disease (COVID-19) in pregnancy; a narrative review. Arch Acad Emerg Med. 2020;8(1):e34.
9. Ramsey PS, Ramin KD. Pneumonia in pregnancy. Obstet Gynecol Clin North Am. 2001;28:553-69. CrossRef

10. Kaposy C, Lafferty L. Overcoming liability concerns in vaccine trials involving pregnant women. Account Res. 2012;19:156-74. CrossRef

11. Brent RL. Risks and benefits of immunizing pregnant women: the risk of doing nothing. Reprod Toxicol. 2006;21:383-9. CrossRef

12. Schwartz DA, Graham AL. Potential maternal and infant outcomes from (Wuhan) coronavirus 2019-nCoV infecting pregnant women: lessons from SARS, MERS, and other human coronavirus infections. Viruses. 2020;12(2):194. CrossRef

13. Ellington S, Strid P, Tong VT, et al. Characteristics of women of reproductive age with laboratory-confirmed SARS-CoV-2 infection by pregnancy status - United States, January 22-June 7, 2020. MMWR Morb Mortal Wkly Rep. 2020;69:769-75. CrossRef

14. Ghema K, Lehlimi M, Toumi H, et al. Outcomes of newborns to mothers with COVID-19. Infect Dis Now. 2021;17:S26669919(21)00065-8. CrossRef

15. Alzamora MC, Paredes T, Caceres D, Webb CM, Valdez LM, La Rosa M. Severe COVID-19 during pregnancy and possible vertical transmission. Am J Perinatol. 2020;37:861-5. CrossRef

16. Chen H, Guo J, Wang C, et al. Clinical characteristics and intrauterine vertical transmission potential of COVID-19 infection in nine pregnant women: a retrospective review of medical records. Lancet. 2020;395:809-15. CrossRef

17. Smith V, Seo D, Warty R, et al. Maternal and neonatal outcomes associated with COVID-19 infection: a systematic review. PLoS One. 2020;15(6):e0234187. CrossRef

18. Yoon SH, Kang JM, Ahn JG. Clinical outcomes of 201 neonates born to mothers with COVID-19: a systematic review. Eur Rev Med Pharmacol Sci. 2020;24:7804-15. CrossRef

19. Yu N, Li W, Kang Q, et al. Clinical features and obstetric and neonatal outcomes of pregnant patients with COVID-19 in Wuhan, China: a retrospective, single-centre, descriptive study. Lancet Infect Dis. 2020;20:559-64. CrossRef

20. Liu D, Li L, Wu X, et al. Pregnancy and perinatal outcomes of women with coronavirus disease (COVID-19) pneumonia: a preliminary analysis. AJR Am J Roentgenol. 2020;215:127-32. CrossRef

21. Khalil A, Kalafat E, Benlioglu C, et al. SARS-CoV-2 infection in pregnancy: a systematic review and meta-analysis of clinical features and pregnancy outcomes. EClinicalMedicine. 2020;25:100446. CrossRef

22. Chen L, Li Q, Zheng D, et al. Clinical characteristics of pregnant women with Covid-19 in Wuhan, China. $N$ Engl $J$ Med. 2020;382:e100. CrossRef

23. Oltean I, Tran J, Lawrence S, et al. Impact of SARS-CoV-2 on the clinical outcomes and placental pathology of pregnant women and their infants: a systematic review. Heliyon. 2021;7(3):e06393. CrossRef

24. Zhang P, Heyman T, Greechan M, et al. Maternal, neonatal and placental characteristics of SARS-CoV-2 positive mothers. J Matern Fetal Neonatal Med. 2021;1-9 [Epub ahead of print]. CrossRef

25. Chen S, Bernstein P, Nair S, et al. A review of 92 obstetric patients with COVID-19 in the Bronx, New York and their peripartum anaesthetic management. Anaesthesiol Intensive Ther. 2021;1-11 [Epub ahead of print]. CrossRef

26. Liu C, Andrusier M, Silver M, Applewhite L, Clare CA. Effect of SARS-CoV-2 infection on pregnancy outcomes in an innercity black patient population. J Community Health. 2021;1-7 [Epub ahead of print]. CrossRef

(C) 2021 Advocate Aurora Health, Inc. 